\title{
Nathalie Schon, L'auto-exotisme dans les littératures des Antilles françaises
}

\section{Francesca Torchi}

\section{Q OpenEdition}

1 Journals

\section{Edizione digitale}

URL: https://journals.openedition.org/studifrancesi/39877

DOI: 10.4000/studifrancesi.39877

ISSN: 2421-5856

\section{Editore}

Rosenberg \& Sellier

\section{Edizione cartacea}

Data di pubblicazione: 1 décembre 2004

Paginazione: $417-418$

ISSN: 0039-2944

\section{Notizia bibliografica digitale}

Francesca Torchi, «Nathalie Schon, L'auto-exotisme dans les littératures des Antilles françaises», Studi Francesi [Online], 143 (XLVIII | II) | 2004, online dal 30 novembre 2015, consultato il 19 mai 2021. URL: http://journals.openedition.org/studifrancesi/39877; DOI: https://doi.org/10.4000/studifrancesi. 39877

Questo documento è stato generato automaticamente il 19 mai 2021.

\section{(c) (1)}

Studi Francesi è distribuita con Licenza Creative Commons Attribuzione - Non commerciale - Non opere derivate 4.0 Internazionale. 


\title{
Nathalie Schon, L'auto-exotisme dans les littératures des Antilles françaises
}

\author{
Francesca Torchi
}

\section{NOTIZIA}

NATHALIE SCHON, L'auto-exotisme dans les littératures des Antilles françaises, Paris, Karthala, 2003 («Lettres du Sud»), pp. 326.

1 Il sentimento dell'auto-esotismo, filo conduttore del saggio critico di Nathalie Shon, è un elemento che caratterizza la cultura della Martinica e della Guadalupa e si riflette nella produzione narrativa contemporanea. L'autrice identifica nell'ambiguità costitutiva delle due società prese in esame l'origine di questo stato esistenziale in cui convivono un senso di estraneità e di appartenenza a se stessi. Partendo da questi presupposti, l'autrice sviluppa una riflessione sulla questione identitaria che mette in secondo piano i rapporti con la Francia, focalizzando l'attenzione sugli aspetti caratteristici della produzione narrativa martinicana e guadalupeana in un'ottica comparatistica. Vengono così evidenziate le tendenze che differenziano le produzioni letterarie e il dibattito culturale delle due isole. Con un approccio che mutua i suoi strumenti critici dalle teorie psicanalitiche ed etnografiche e che privilegia alcuni dei maggiori esponenti della letteratura dell'una e dell'altra isola, Nathalie Schon mostra come possa prendere forma in letteratura l'auto-esotismo e tenta, nel contempo, di fornirne una definizione esaustiva, facendo riferimento non soltanto alle note categorie Centro e Periferia, ma anche a quelle del Mito e dell'Utopia.

2 Il corpus considerato è composto principalmente dalle opere di Partick Chamoiseau e di Raphaël Confiant per la Martinica, e da quelle di Gisèle Pineau e di Maryse Condé per la Guadalupa. Nell'ampia introduzione, in cui si ripercorrono le tappe della riflessione che il volume approfondisce, vengono prima di tutto resi manifesti i presupposti teorici dello studio proposto, collocati all'interno di quegli studi francofoni influenzati dalla critica postcoloniale, il cui teorico più autorevole è Jean-Marc Moura. La questione 
dell'auto-esotismo è per Nathalie Schon un nucleo problematico irrisolto per la letteratura antillese di Martinica e Guadalupa, la cui storia, ancora oggi, è inscindibilmente legata alla Francia. La domanda cui i vari scrittori tentano di rispondere sembra per questo essere: "peut-on à la fois être d'ici et de là-bas sans demeurer un éternel étranger?" (p. 17). Per dare una risposta a questo dilemma, però, gli scrittori martinicani e quelli guadalupeani sembrano reagire con un atteggiamento mentale e letterario molto diverso. I primi, tendenzialmente, affermano con convinzione l'“existence d'un contexte antillais" (p. 17), mentre i secondi, esprimendo una poetica divergente, si dimostrano maggiormente rivolti all'introspezione e all'accettazione del "déchirement entre les Antilles et la France [...] comme constitutif de leur identité" (p. 18). In quest'ottica, ed in relazione anche al rapporto problematico tra Centro e Periferia, la scrittura martinicana reagisce all'alienazione culturale attraverso un lavoro di riappropriazione delle proprie specificità e di ricostituzione del punto di vista antillese, spesso rendendo caricaturale, per contro, quello francese. Nelle opere guadalupeane, invece, non appare evidente questo confronto costante con la Francia, mentre spicca il tema del distacco dall'isola natale da parte dei personaggi per potersene poi riappropriare, proprio grazie all'allontanamento, alla presa di distanza.

Tutta la prima parte del volume è dedicata al concetto di 'auto-exotisme', alla sua storia e alla sua evoluzione nella società antillese e nelle manifestazioni letterarie. Il capitolo si struttura attorno ad una messa a confronto di personaggi e scrittori dell'una e dell'altra isola come tappe della genesi di due reazioni differenti, di due poetiche dell'auto-esotismo. Tra i personaggi storici l'autrice propone, rispettivamente per Martinica e Guadalupa, Schœlcher e Delgrès, per rappresentare le prime manifestazioni letterarie locali nelle quali traspare la questione identitaria. Fra gli scrittori prende in considerazione Daniel Thaly da un lato e Saint-John Perse dall'altro, seguiti da Joseph Zobel e Michèle Lacrosil, come interpreti autoctoni della complessa identità antillese. Prendendo poi in esame le opere degli scrittori contemporanei più significativinell'ottica di lettura critica qui proposta - per rappresentare le due isole, l'autrice mette in evidenza, nella seconda parte, gli elementi chiave che permettono di individuare poetiche letterarie che rispondono all'auto-esotismo diametralmente opposte: gli scrittori martinicani - rappresentati qui soprattutto da Patrick Chamoiseau e dal suo romanzo Texaco - si esprimono "par une écriture symbolique ancrée dans l'île" (p. 81), mentre i guadalupeani, come Maryse Condé, "par une écriture métaphorique de la réalité" (p. 81). In ambito martinicano, la questione identitaria è affrontata attraverso la creazione di un ordine nuovo, di teorie e di miti "comme légitimation du combat politique" (p. 83); nei romanzi guadalupeani è invece evidente la messa in scena di personaggi che fuggono dall"'insularité étouffante" (p. 82) e che danno maggior peso all'espressione della propria interiorità. Tra i vari temi che il filo conduttore dell'auto-esotismo implica, l'autrice individua nella trattazione della follia il momento privilegiato in cui queste concezioni antitetiche si esplicitano: "la folie provoque donc chez Maryse Condé l'éclatement de la prison insulaire et entraîne ou plutôt est une acceptation d'appartenances multiples, tout en figurant la menace de l'assimilation/perte d'identité chez Patrick Chamoiseau" (p. 82).

4 Nathalie Schon affronta poi il delicato problema delle scritture maschili e femminili ed il loro rapporto in relazione all'esotico e all'utopico, alla presentazione cioè di modelli nuovi che risolvano il disagio culturale e identitario antillese. In questo senso, come si legge nei romanzi di Gisèle Pineau e in quelli di Maryse Condé, per i personaggi femminili l'auto-esotismo è una condizione esistenziale conseguente al bisogno di 
allontanarsi dalla propria condizione di partenza, di fuggire - seppur in modo doloroso - e di conquistare un ruolo sociale attivo. Le conclusioni di Nathalie Schon intendono mettere in rilievo anche i limiti e le rigidità delle due poetiche analizzate. A proposito dei due scrittori martinicani considerati, infatti, afferma che "Patrick Chamoiseau et Raphaël Confiant voient en l'écrivain antillais le guide, celui qui sait, et en la littérature antillaise, une affaire de famille, loin du 'bruhaha' des littératures mondiales" (p. 298), mentre la scrittura di Maryse Condé rischia, proprio per il suo "déracinement", di essere anche una scrittura dell'indifferenza.

Mettere a confronto gli elementi di differenza della poetica martinicana e di quella guadalupeana porta Nathalie Schon ad elaborare una personale teoria letteraria in cui l'auto-esotismo risulta essere la chiave per aprirsi all'Altro. L'autrice individua in particolare nel nomadismo espresso dalla letteratura guadalupeana il sentimento dell'ospitalità, pulsione di vera apertura, atteggiamento non assimilatore, che integra "l'étrangeté dans une sphère habituellement réservée au familier" (p. 300), affermando che "les auteurs guadeloupéens étudiés n'en rejettent donc pas moins une poétique ayant pour but la définition d'un régionalisme univoque et sans fantaisie, qu'il soit local ou global, pour ouvrir la voie à une poétique de l'exotique (p. 302). 